\title{
Research on Construction of New-Typed Equipment Green Maintenance Facility
}

\author{
Weijie Liang ${ }^{1, a}$, Xingxin $\mathrm{Li}^{2, \mathrm{~b}}$, Weihua Dong ${ }^{3, \mathrm{c}}$ and Jinna Jia ${ }^{4, \mathrm{~d}}$ \\ ${ }^{1}$ Institute of Mechanical Engineering, Mechanical Engineering College , Beixin Street, Shijiazhuang \\ City, Hebei Province, China, 050000. \\ ${ }^{2}$ Maintenance Engineering Institute of Equipment Demand and Management, Mechanical \\ Engineering College, West Heping Road, Shijiazhuang City, Hebei Province, China, 050003. \\ ${ }^{3}$ Dept. of 72465, North Qinglongshan Road, Jinan City, Shandong Province, China, 250022. \\ ${ }^{4}$ College of Information Technology and Culture Management, Hebei Institute of Communications, \\ Xinan Street of Luancheng Zone, Shijiazhuang City, Hebei Province, China, 051430. \\ aliang_weijie@163.com, ${ }^{b}$ Ixx_1226@sina.com, 'Iwj.mei@gmail.com, djjn0110@163.com
}

Keywords: New-typed equipment, green maintenance, facility construction

\begin{abstract}
This paper outlines the basic structure of equipment maintenance work, analyzes the conditions and necessity for the emergence of green maintenance, from the different aspects of quantitative requirements, maintenance method, maintenance materials, maintenance energy, maintenance process and maintenance products, analyzes the basic connotation and requirements of green maintenance. For the different types of facilities, such as business management, repair work, test area, teaching \& training and support aids, from the different view of system demonstration, system design, information system construction, tool-sets matching and maintenance methods implementation, puts forward the main ideas and measures of the demonstration, design, construction and operation of green maintenance facilities.
\end{abstract}

\section{Introduction}

Equipment maintenance is a servicing and repair activity to maintain, restore the the equipment to the defined technical condition or to improve the equipment's performance, which is an important way in the formation of the equipment supportability. According to the property and purpose of maintenance, it can be divided into preventive maintenance, corrective maintenance and improvable maintenance; according to the facility and level, it can be classified into organizational-level, intermediate-level maintenance and depot-level maintenance.

Maintenance is an important activity in the equipment operation phase, the consumed resource, energy in the maintenance activities in the equipment life-cycle and the quantity of all kinds of waste generated in all the maintenance processes are relatively large. In the composition of the equipment life-cycle cost, the maintenance activities cost is usually the largest part. With the development of science and technology, the new equipment become more and more complex, with the increasingly high degree of technology, the corresponding required maintenance work also become more and more complex, the consumption of various resources are more and more and gradually bring a lot of environmental pollution problems.

With the increasingly serious environmental problems, since the 90s of the 20th century, national environmental protection strategy began a new turning point, the global industrial structure adjustment showing new trend in green strategy, which is developing in the direction toward the reasonable resources utilization, less waste generation, and non-pollution or less-pollution to the environment. Green production, green design, green manufacturing, re-manufacturing engineering and other green ideas, green technology came into being, the global set off a "green wave".

The emergence of the concept of green maintenance is the result of people's thinking on this issue. Green maintenance, is a kind of efficient, high-quality, low-cost and non-polluting maintenance based on the concept of sustainable society development, and it is a kind of the advanced technology 
and process unit, with minimal resources and energy consumption, to avoid environmental pollution, waste generation to minimize the amount of maintenance. Green maintenance mode is a kind of modern maintenance mode considering the environmental impact and resource utilization. Therefore, the green maintenance is a kind of intensive, more reasonable, more environmentally friendly maintenance[1-4].

Equipment maintenance facilities is a is a collective name for the equipment maintenance required permanent or semi-permanent buildings, site and ancillary tool-sets, including repair facilities, maintenance workshops, maintenance equipment warehouse, etc., which is an important foundation for the implementation of equipment maintenance conditions. At present, the systematical construction of all kinds of new-typed equipment maintenance facilities should be based on the concept of green maintenance design, and carry out the thought and principle of green maintenance in multiple aspects of facilities planning, condition construction and method implementation, to let the new equipment maintenance activities can minimize the consumption of resources and energy, reduce environmental pollution, improve the overall efficiency and achieve sustainable development.

\section{The main connotation of green maintenance}

In addition to general maintenance to achieve the required provisions to maintain and restore the state of the equipment, green maintenance's targets should also be used in the repair method of green method, green materials should be used in the equipment maintenance spares, green energy should be used in the energy consumption, pollution prevention methods should be implemented in the maintenance process, so that repaired products can meet green requirements, as shown in Fig. 1.

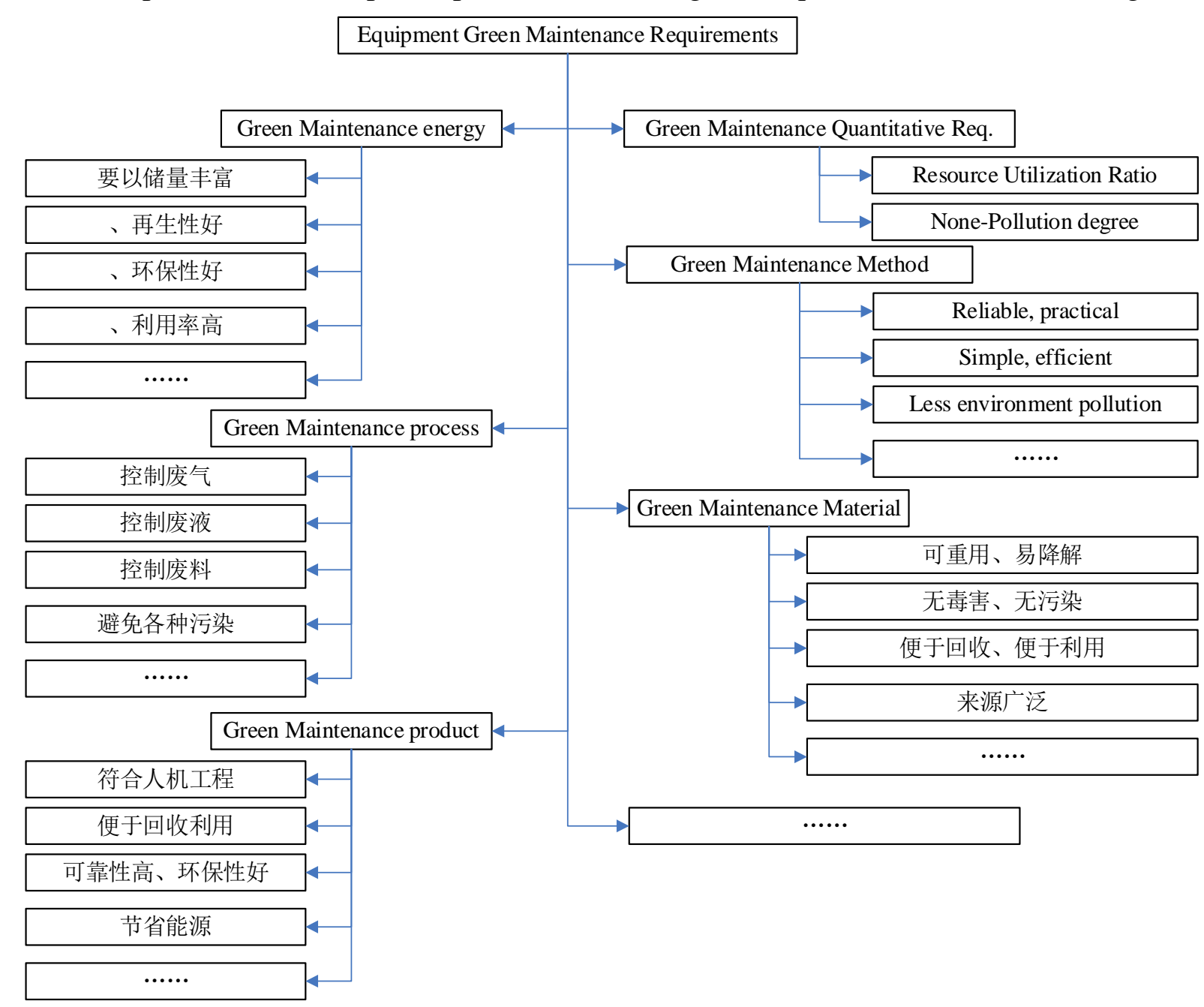

Fig. 1 the main requirements/factors of green maintenance 
Quantitative requirements of green maintenance. The green maintainability quantitative requirements are mainly measured in two indicators of resource utilization rate and non-pollution degree. The resource utilization rate refers to the ratio of the number of units that can be reused after equipment fault and the total number of product units. There are two situations in the number of units that can be reused after equipment fault, which are the unit after failure that can be used as a raw material reuse unit, and the unit after repair that can be used as parts or components. The pollution caused by the maintenance of the production is varied, some influence the air, some pollute water, some produce noise, and some produce microwave and harmful radiation etc..For the quantitative requirements in pollution-free green maintainability, it can be described in relatively non-pollution degree, which can be defined as the relative ratio between the actual pollution value of product maintenance and the maximum allowable value of the state environmental protection department.

Green maintenance method. Maintenance methods implemented must be reliable and practical, simple and efficient, all kinds of methods and techniques used in the maintenance work should be able to effectively reduce or eliminate the environmental impact of the maintenance activities in the equipment operation phase. According to the requirement of green maintenance, we must research and improve the surface engineering technology, machining technology, parts cleaning technology, heat treatment technology and other types of maintenance processes and technology, so as to reduce the energy consumption and pollution in the process of maintenance.

Green maintenance materials. Based on the principle of reusable, easy degradation, non-poison, non-pollution, convenient recovery, convenient utilization, wide source and others characteristics, select all kinds of equipment maintenance material and consumption material, reduce the use of rare and expensive materials and toxic and hazardous materials, so as to reduce pollution sources.

Green maintenance energy. Based on the principle of rich reserves, good reproduction, good environmental protection, high utilization ratio and others characteristics, and according to the type of equipment maintenance work (such as small parts disassembly, oil parts clear, heavy corrosion parts disassembly) required, select the type of energy required for equipment maintenance.

Green maintenance process. Adopt various measures to avoid electromagnetic pollution, noise pollution and radioactive pollution generated in the maintenance process, or ensure that the pollution can not be reduced is far away from residential areas and strengthen management and control, strengthen the of all kinds of waste gas, waste water, waste treatment, and avoid the pollution to the environment.

Green maintenance products. Take reduction of maintenance on the environment effect as the main goal, and take the equipment maintenance is in accordance with ergonomics, easy recycling utilization, high reliability, environmental protection and energy saving, and others factors as the evaluation index, and promote the implementation of green maintenance philosophy.

\section{The construction of green maintenance facilities}

Green maintenance facilities mainly include business management facilities, repair work facilities , test area facilities , teaching \& training facilities and support-aid facilities and others facilities (such as Figure 2). These facilities not only consume large quantities of energy and resources in the process of construction and operation, but also have a corresponding impact on the evaluation index of all elements of the green maintenance system in its life-cycle. Therefore, in the construction of maintenance facilities planning, design, building and post-finishing processes should firmly establish the concept of green, full implement the green strategy.

Maintenance facilities construction system demonstration. In maintenance facilities design and demonstration stage, we must conduct in-depth research of the maintenance facility requirement, local climate and hydrology and other natural conditions, current materials development and construction technology, related or similar facilities construction experience, and others factors, fully demonstrate the applicability, technical feasibility, economical efficiency, comprehensive benefits and risks, on the basis of the comparison and optimization of various factors, such as the facilities 
requirements, the regional characteristics, maintenance requirements, and others factors, put forward the site, layout and facilities of maintenance facilities planning advice.

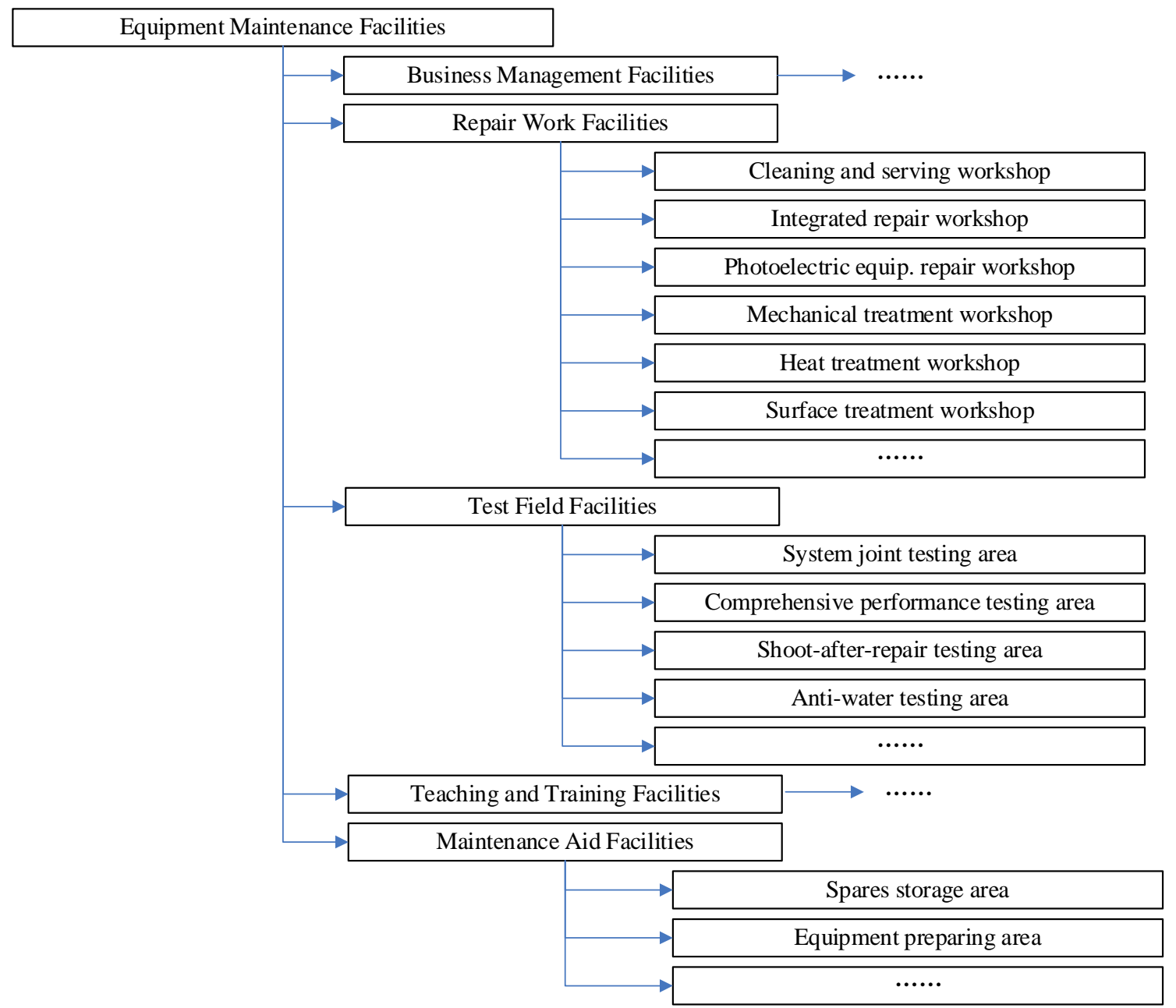

Fig. 2 the mainly components of maintenance facilities

Maintenance facilities construction system design. According to the variety, quantity and maintenance cycle of the corresponding facilities for equipment maintenance requirements, calculate the facility area requirements, optimize the layout of repair line and station, on the basis of the process and management of repairing operation, control the scale, optimize the allocation, improve the efficiency. Improve the effect of energy saving facilities using new technology, use high performance and good durability materials, use natural lighting and ventilation as more as possible, reduce material and energy consumption in the process of construction, operation and maintenance. Use industrial assembly system and decoration, apply the site dry operation method, improve the construction precision, shorten the construction period, reduce energy consumption, and reduce environmental pollution in the process of building construction. Facilities should be in line with the public aesthetic standards, follow the traditional customs, concise and clear, reflect the order, in line with the safety norms. Facilities signs should be complete, with the correct color, appropriate size and reasonable use.

Facilities information construction. Establish the network environment covering the various links and agencies nodes of the equipment maintenance, unify data standards and interface standards of all kinds of maintenance equipment and information acquisition equipment, realize the accurate automation of information acquisition, the visualization of resource allocation and the information sharing. Extend the application of information technology in maintenance management, let the large complex data organization to become easy to find and use the maintenance and management information, use information flow to make the human resources flow, technological process flow, material flow and capital flow in order. 
Tool-sets matching. The relate tool-sets should be based on the operation location, professional requirements, equipment performance parameters, and take the technology reform measures such as the parameters integration, the function integration, the specialties combination and the quantity merger to reduce the types of repetitive maintenance equipment in different specialties, elite the maintenance tool series, optimize the maintenance tool spectrum, decrease the number, so to gradually form a series of maintenance tool-sets. According to the repair task in operation, carry out a flexible assembly to form the equipment repair line or repair unit.

Green maintenance method's comprehensive operation. Green maintenance method includes reasonable support mode, maintenance process and advanced maintenance technology. Its main characteristics is to reduce energy, material consumption and waste emissions.

Firstly, apply the equipment maintenance experts' knowledge and experience comprehensively, develop remote maintenance system based on the common network. Improve the testing ability of the fault detection system, develop small-size, light-weight, modular, multi-functional testing tool-sets. Ensure the real-time support spares can meet requirements, reduce the amount of equipment in-repair. Implement proactive maintenance and accurate maintenance to reduce the shortage of the insufficient maintenance, excessive maintenance and unresponsive maintenance.

Secondly, design according to the equipment repair properties, repair quantity and equipment types, set production process for the equipment with large-quantity repair tasks and maintenance procedures, set unit operation process for the equipment with the testing-maintenance and small-quantity maintenance tasks.

Thirdly, make the new technology of equipment maintenance and repair process match the service conditions, and meet the technological advantages, environment coordination and economy requirements. Through the digital reconstruction, re-design and optimization for the tool-sets of the maintenance process, and combination of sensors, networking and other technologies to improve the performance testing, oil and components identification, original repair and other technical standards, so as to simply the equipment fault diagnosis and shorten the maintenance time in the repair processes, take as little as possible for non-procedure disassembly, replacement parts and oil and consumption of raw materials.

Fourthly, carry out a special research for the more-consume, long-time, environmental-pollution parts cleaning work, control the cleaning effect and the environmental impact result, find the ways of high efficiency cleaning and less environmental impact. Such as the use the high pressure water cleaning equipment to clean the large parts, use the dry ice to clean heavy-oil components and electrical equipment, use the ultrasonic wave to clean the small parts, the cleaning efficiency of which list above is relatively high. Treat the waste water and the domestic sewage separately, to achieve the economic and environmental protection of the green requirements.

\section{Summary}

Environmental problem is a major problem facing the current sustainable development, the full implementation of the green maintenance of large-scale complex products is conducive to reduce consumption and reduce pollution. To carry out the construction of equipment maintenance facilities, we must fully carry out the transformation from the traditional concept to the green maintenance concept, put forward the green maintenance facilities construction from the demonstration, plan, design, building and operation stage, so as to lay a solid foundation for green maintenance.

\section{References}

[1] Zhang Huimin, Wang Shengfeng, Li Qingquan. Issues on Resource Conservation and Green Equipment Maintenance Technology[J]. ACTA ARMAMENTAR II. Vol.31 Suppl.2, 2012.12, pp 179-182.

[2] Zhou Hong, Gan Maozhi. Green maintenance general remarks[M]. Beijing, National Defense Industry Press, 2008. 
[3] Ma Shining, Sun Xiaofeng. Green equipment maintenance development[J]. China Surface Engineering, 2006,10, pp36-37.

[4] Lin Guomin, Sun Qin, Li Yanhua. Analysis of green maintenance and green maintainability[J]. Aviation maintenance. 2004.2, pp.51-53. 